(c) American Dairy Science Association, 2004.

\title{
Disappearance of Docosahexaenoic and Eicosapentaenoic Acids from Cultures of Mixed Ruminal Microorganisms
}

\author{
A. A. AbuGhazaleh and T. C. Jenkins \\ Department of Animal and Veterinary Sciences, \\ Clemson University, Clemson, SC 29634
}

\section{ABSTRACT}

Previous studies showed conflicting results regarding the ability of ruminal microorganisms to hydrogenate docosahexaenoic acid (C22:6, DHA) and eicosapentaenoic acid (C20:5, EPA). To determine the disappearance of DHA and EPA from mixed ruminal cultures, 2 ruminal in vitro experiments were conducted using graded levels of DHA and EPA. The first experiment examined DHA added at $0,5,10,15$, and $20 \mathrm{mg}$ per culture flask. In the second experiment, EPA was added at 0, 5, 10, and $15 \mathrm{mg}$ per culture flask. Docosahexaenoic acid and EPA were incubated in triplicate in $125-\mathrm{mL}$ flasks, and $5 \mathrm{~mL}$ of culture contents was taken at 0,12 , and $24 \mathrm{~h}$ for fatty acid analysis by gas liquid chromatography. After $24 \mathrm{~h}$ of incubation, 4.1, 4.1, 4.0, and $3.3 \mathrm{mg}$ of DHA disappeared from the $5,10,15$, and $20 \mathrm{mg}$ of DHA cultures, respectively. In the second experiment, 5, 8.3, and $7.1 \mathrm{mg}$ of EPA disappeared after $24 \mathrm{~h}$ of incubation for the 5-, 10-, and 15-mg EPA cultures, respectively. Addition of DHA to cultures increased trans-C18:1 fatty acid accumulation by $105,91,82$, and $74 \%$ for the 5 , 10-, 15-, and 20-mg cultures, respectively, compared with control. The addition of EPA increased trans-C18:1 fatty acid accumulation by 56, 64, and 55\% for the 5-, 10-, and 15-mg EPA cultures, respectively, compared with control. Addition of DHA and EPA to cultures caused a reduction in C18:1 n-9 and C18:2 $n-6$ biohydrogenation compared with control. Results from these experiments clearly demonstrate the ability of ruminal microorganism to transform DHA and EPA to other fatty acids causing their disappearance from cultures. (Key words: docosahexaenoic acid, eicosapentaenoic acid, biohydrogenation)

Abbreviation key: BH = biohydrogenation, DHA = docosahexaenoic acid, EPA = eicosapentaenoic acid, FA = fatty acid.

Received July 7, 2003

Accepted September 26, 2003

Corresponding author: A. A. AbuGhazaleh; e-mail: aabugha@ clemson.edu.

\section{INTRODUCTION}

There is increasing information about the nutritional and health benefits of the long chain omega-3 polyunsaturated fatty acids (FA), docosahexaenoic acid (C22:6, DHA) and eicosapentaenoic acid (C20:5, EPA) for humans (Simopoulos, 1998). Major health benefits ascribed to omega-3 FA include reduced risk of cardiovascular disease, diabetes, hypertension, arthritis, and cancer (Leaf and Weber, 1988; Leaf and Korng, 1998; Sheard, 1998). There is also some evidence that the pathophysiology of major depression is associated with a deficiency of omega-3 FA (Maes et al., 1999).

Marine oils derived from fish or algae are the major source of omega-3 FA in animal diets. Different attempts were made to increase the concentration of DHA and EPA in milk fat by adding fish oil and algae to cow diets (Franklin et al., 1999; Offer et al., 1999; Chilliard et al., 2000; Donovan et al., 2000). However, the apparent efficiency of transfer of these FA from diets to milk was very low ( $<20 \%$; Franklin et al., 1999; Donovan et al., 2000). These low transfer efficiencies for DHA and EPA were attributed to their association with plasma lipoproteins, which are not good substrates for mammary lipoprotein lipase (Mansbridge and Blake, 1997), or to their preferential partition towards other tissues in the body (Ashes et al., 1992). However, Doreau and Chilliard (1997) attributed their low transfer efficiencies to extensive biohydrogenation (BH) in the rumen. In contrast to Doreau and Chilliard findings, Ashes et al. (1992) reported negligible BH for DHA and EPA when fish oil was incubated with ruminal contents in vitro for $24 \mathrm{~h}$ under anaerobic conditions. Therefore, ruminal $\mathrm{BH}$ of DHA and EPA remains a subject of debate.

A previous study by Gulati et al. (1999) reported a reduction in $\mathrm{BH}$ for DHA and EPA when fish oil was incubated at a level higher than $1 \mathrm{mg} / \mathrm{mL}$ of ruminal fluid using batch cultures. Therefore, our studies were initiated to examine the disappearance of DHA and EPA from ruminal cultures when these FA were incubated at different levels. We are not aware of any published study that used a pure form of free DHA or EPA to examine their disappearance from mixed ruminal cultures. 


\section{MATERIALS AND METHODS}

Docosahexaenoic acid and EPA were purchased from Sigma-Aldrich Chemical Company ( $>99 \%$ purity; St. Louis, MO), dissolved in ethanol, and stored at $-5^{\circ} \mathrm{C}$ until used. Ruminal contents were obtained from a fistulated Holstein cow and strained through 2 layers of cheesecloth and transported to the laboratory in a sealed container and used within 20 min. Treatments for the first experiment were control (no DHA) or control with $5,10,15$, or $20 \mathrm{mg}$ of added DHA. Treatments in the second experiment were control (no EPA) or control with 5, 10, or $15 \mathrm{mg}$ added EPA. Assuming DHA and EPA each approximately represent $10 \%$ fish oil FA, the $5,10,15$, and $20 \mathrm{mg}$ of added $\mathrm{FA}$ would be equivalent to incubating fish oil at $1,2,3$, and $4 \mathrm{mg} / \mathrm{mL}$ of ruminal fluid. Docosahexaenoic acid and EPA in ethanol (400 $\mu \mathrm{L}$ ) were added directly into each culture. Cultures were maintained in $125-\mathrm{mL}$ Erlenmeyer flasks containing $500 \mathrm{mg}$ of finely ground TMR, $10 \mathrm{~mL}$ of the strained ruminal fluid, $40 \mathrm{~mL}$ of media, and $2 \mathrm{~mL}$ of reducing solution according to Goering and VanSoest (1970). The TMR used in cultures was a 50:50 blend of forage (corn silage) and concentrate (corn, soybean meal minerals, and vitamins). Cultures were run in triplicate at $39^{\circ} \mathrm{C}$ under anaerobic conditions. To determine the initial and final DHA and EPA concentrations, 5-mL samples were taken from each culture flask at 0,12 , and $24 \mathrm{~h}$ while being stirred with a magnetic bar under a stream of $\mathrm{CO}_{2}$, placed immediately in an ice bath, and then stored at $-5^{\circ} \mathrm{C}$.

Samples were freeze dried and then methylated according to Kramer et al. (1997) and analyzed for FA by GLC. Methylated FA were separated using a fused silica capillary column $(100 \mathrm{~m} \times 0.25 \mathrm{~mm}$, i.d. $\times 0.20 \mu \mathrm{m}$ thickness), CP-SiL88 (Chrompack, Ravitan, NJ). The split ratio in the injector port $\left(160^{\circ} \mathrm{C}\right)$ was $100: 1$ with a column flow of $1.5 \mathrm{~mL} / \mathrm{min}$ of He. Oven temperature was programmed for $160^{\circ} \mathrm{C}$ for $4 \mathrm{~min}$, then increased from 160 to $215^{\circ} \mathrm{C}$ at $4^{\circ} \mathrm{C} / \mathrm{min}$, and finally held at $215^{\circ} \mathrm{C}$ for $21 \mathrm{~min}$. The injector and detector temperatures were $250^{\circ} \mathrm{C}$. Heptadecanoic acid (C17:0) was added to all samples as an internal standard. Data were analyzed by ANOVA using the general linear model procedure of SAS (SAS Inst., Inc., Gary, NC). Orthogonal contrast statements were used to compare treatments effect at each sampling time $(0,12$, and $24 \mathrm{~h})$. Planned comparisons were: 1) control versus DHA and EPA, 2) linear effect, and 3) quadratic effect. Cubic effect was tested and found not significant. Significance was determined at $P<0.10$.

\section{RESULTS}

The changes in mg of FA in ruminal cultures with the addition of DHA and EPA are presented in Tables
1 and 2 . After $12 \mathrm{~h}$ of incubation, disappearance of DHA from cultures showed a linear effect $(P<0.10$, Table 1). Disappearance was highest with the $5-\mathrm{mg}$ DHA level averaging $3.0 \mathrm{mg} /$ culture, intermediate with 10 - and 15- $\mathrm{mg}$ of DHA levels (2.5 and $2.2 \mathrm{mg}$ ), and least with the 20-mg DHA level (1.4 mg; Table 1). The disappearance of DHA from cultures was further increased after $24 \mathrm{~h}$ of incubation for all levels, averaging 4.1, 4.1, 4.0, and $3.3 \mathrm{mg}$ per culture for the 5-, 10-, 15-, and 20-mg DHA levels, respectively (Table 1). Total DHA disappeared over $24 \mathrm{~h}$ was similar for the 5-, 10-, and 15-mg DHA levels, and they were all higher than the 20-mg DHA level. As for EPA disappearance, 4.3, 5.4, and 4.3 $\mathrm{mg}$ of EPA disappeared after $12 \mathrm{~h}$ of incubation for the 5-, 10-, and 15-mg EPA levels, respectively, resulting in quadratic effect $(P<0.10$; Table 2$)$. Disappearance of EPA increased as incubation time increased from 12 to $24 \mathrm{~h}$, resulting in the 5 -mg cultures being cleared of EPA and the majority of the EPA being lost in the $10-$ and $15-\mathrm{mg}$ cultures (8.2 and $7.1 \mathrm{mg}$ disappeared, respectively). The disappearance of EPA from cultures over time was much higher than that of DHA (Figure 1). After $24 \mathrm{~h}$ of incubation, some unidentified longchain FA were detected around DHA and EPA peaks in cultures (Figure 2; Tables 1 and 2).

The addition of DHA and EPA to cultures at different levels affected the BH of other FA (Tables 1 and 2). After $24 \mathrm{~h}$ of incubation, trans-C18:1 FA concentrations were higher $(P<0.10)$ with added DHA and EPA compared with control. Concentrations of trans-C18:1 FA were highest for the 5-mg DHA level and there was a linear $(P=0.06)$ decrease for trans-C18:1 FA concentration with increasing DHA level (Table 1). Unlike control cultures where the concentration of C18:1 n-9 decreased after the $24 \mathrm{~h}$ of incubation as a result of $\mathrm{BH}$, addition of DHA increased $(P<0.10)$ the concentration of C18:1 $\mathrm{n}-9$, while the addition of EPA caused no changes in the concentration of C18:1 n-9 in cultures after the 24 $\mathrm{h}$ of incubation. Addition of DHA and EPA to cultures also resulted in no changes in the concentration of C18:0 after $24 \mathrm{~h}$ of incubation compared with control, where the concentration of C18:0 increased by approximately $150 \%$ as a result of complete $\mathrm{BH}$ of unsaturated FA (Tables 1 and 2). After $24 \mathrm{~h}$ of incubation, the concentration of short-chain FA $(<\mathrm{C} 16: 0)$ in ruminal cultures were linearly decreased $(P<0.10)$ as the levels of DHA and EPA in cultures increased (Tables 1 and 2).

\section{DISCUSSION}

The principal objective of these studies was to assess the disappearance of DHA and EPA from ruminal cultures when incubated at different levels. Disappearance of DHA and EPA from cultures can be caused 
Table 1. Changes in milligrams of fatty acids per culture flask over time with added docosahexaenoic acid (DHA) (mg/flask).

\begin{tabular}{|c|c|c|c|c|c|c|c|c|c|}
\hline \multirow{2}{*}{ Fatty acids } & & \multicolumn{6}{|c|}{ Treatment } & \multicolumn{2}{|c|}{ Contrast $^{1}$} \\
\hline & & Control & $5 \mathrm{mg}$ DHA & 10mg DHA & 15mg DHA & 20mg DHA & SE & Lin & Quad \\
\hline \multicolumn{10}{|l|}{$<\mathrm{C} 16: 0$} \\
\hline & $0-\mathrm{h}$ & 14.5 & 14.7 & 14.1 & 13.7 & 13.7 & 0.53 & 0.20 & 0.58 \\
\hline & $12-\mathrm{h}$ & 21.0 & 20.3 & 19.4 & 18.4 & 18.6 & $0.30 *$ & 0.03 & 0.17 \\
\hline & $24-4$ & 25.4 & 24.3 & 23.3 & 22.9 & 23.0 & $0.27 *$ & 0.03 & 0.08 \\
\hline C18:0 & $0-\mathrm{h}$ & 10.3 & 10.1 & 10.2 & 10.1 & 10.0 & 0.13 & 0.21 & 0.66 \\
\hline & $12-\mathrm{h}$ & 20.6 & 10.4 & 10.3 & 10.2 & 10.3 & $0.06^{*}$ & 0.21 & 0.10 \\
\hline & $24-4$ & 25.8 & 11.0 & 10.3 & 10.2 & 10.1 & $0.07 *$ & 0.01 & 0.01 \\
\hline C18:1 cls-9 & $0-\mathrm{h}$ & 8.1 & 7.9 & 7.5 & 7.8 & 7.1 & 0.33 & 0.26 & 0.91 \\
\hline & $12-\mathrm{h}$ & 5.6 & 7.8 & 7.9 & 9.2 & 8.1 & $0.13^{*}$ & 0.08 & 0.05 \\
\hline & $24-4$ & 4.4 & 7.3 & 8.4 & 8.9 & 7.9 & $0.41^{*}$ & 0.21 & 0.07 \\
\hline C18:1 trans & $0-\mathrm{h}$ & 1.6 & 1.6 & 1.5 & 1.7 & 1.4 & 0.09 & 0.17 & 0.70 \\
\hline & $12-\mathrm{h}$ & 6.8 & 11.0 & 9.4 & 9.2 & 7.9 & $0.36^{*}$ & 0.03 & 0.72 \\
\hline & $24-4$ & 7.2 & 15.3 & 14.1 & 13.5 & 12.3 & $0.53 *$ & 0.06 & 0.65 \\
\hline \multicolumn{9}{|l|}{ C18:2 } & 0.36 \\
\hline & $12-\mathrm{h}$ & 4.8 & 5.9 & 7.6 & $\begin{array}{r}12.4 \\
7.3\end{array}$ & 8.4 & $0.45^{*}$ & 0.07 & 0.58 \\
\hline & $24-4$ & 1.9 & 2.2 & 3.1 & 3.2 & 3.7 & $0.29 *$ & 0.04 & 0.42 \\
\hline \multicolumn{6}{|l|}{ C18:3 } & 0.6 & & 0.09 & 0.50 \\
\hline & $12-\mathrm{h}$ & 0.2 & 0.2 & 0.2 & 0.3 & 0.3 & 0.05 & 0.54 & 0.50 \\
\hline & $24-4$ & 0.0 & 0.0 & 0.0 & 0.0 & 0.0 & 0.0 & 0.00 & 0.00 \\
\hline \multicolumn{8}{|l|}{$\mathrm{C} 22: 0$} & & \\
\hline & $12-\mathrm{h}$ & 0.2 & 0.2 & 0.1 & 0.1 & 0.2 & $>0.01 *$ & 0.27 & 0.03 \\
\hline & $24-4$ & 0.2 & 0.2 & 0.1 & 0.1 & 0.1 & $>0.01^{*}$ & 0.40 & 0.51 \\
\hline \multicolumn{10}{|l|}{$\mathrm{C} 24: 0$} \\
\hline & $\begin{array}{l}0-\mathrm{h} \\
12-\mathrm{h}\end{array}$ & $\begin{array}{l}0.1 \\
0.2\end{array}$ & $\begin{array}{l}0.1 \\
0.2\end{array}$ & $\begin{array}{l}0.1 \\
0.2\end{array}$ & $\begin{array}{l}0.1 \\
0.2\end{array}$ & $\begin{array}{l}0.1 \\
0.2\end{array}$ & $\begin{array}{l}>0.01 \\
>0.01\end{array}$ & $\begin{array}{l}0.21 \\
0.62\end{array}$ & $\begin{array}{l}0.23 \\
0.52\end{array}$ \\
\hline & $24-4$ & 0.2 & 0.2 & 0.2 & 0.2 & 0.2 & 0.02 & 0.07 & 0.09 \\
\hline C22:6 (DHA) & 0 -h & 0.0 & 5.2 & 10.2 & 14.6 & 18.6 & $0.09 *$ & $<0.01$ & 0.03 \\
\hline & $12-\mathrm{h}$ & 0.0 & 2.2 & 7.8 & 12.4 & 17.2 & $0.05^{*}$ & $<0.01$ & 0.01 \\
\hline \multirow{2}{*}{\multicolumn{10}{|c|}{ Others $^{2}$}} \\
\hline & & & & & & & & & \\
\hline & $0-\mathrm{h}$ & 0.0 & 0.1 & 0.0 & 0.1 & 0.1 & 0.03 & 0.71 & 0.17 \\
\hline & $12-\mathrm{h}$ & 0.3 & 1.2 & 0.5 & 0.3 & 0.3 & $0.03 *$ & $<0.01$ & $<0.01$ \\
\hline & \multicolumn{8}{|c|}{ Total FA/flask } & 0.09 \\
\hline Helar Th/Hash & $0-\mathrm{h}$ & 48.3 & 54.5 & 57.5 & 61.0 & 64.1 & $2.27 *$ & 0.06 & 0.85 \\
\hline \multirow{3}{*}{ DHA disap ${ }^{3}$} & $24-\mathrm{h}$ & 64.8 & 64.4 & 66.9 & 70.8 & 73.9 & $1.17^{*}$ & 0.02 & 0.49 \\
\hline & $12-\mathrm{h}$ & 0.0 & 3.0 & 2.5 & 2.2 & 1.4 & 0.05 & $<0.01$ & 0.12 \\
\hline & $24-4$ & 0.0 & 4.0 & 4.1 & 4.0 & 3.3 & 0.15 & 0.07 & 0.11 \\
\hline
\end{tabular}

${ }^{1}$ Contrast $=$ probability of a linear $($ Lin) or quadratic (Quad) effect of the level of added DHA.

${ }^{2}$ Unidentified long-chain fatty acids.

${ }^{3} \mathrm{DHA}$ disappearance (mg/flask).

$*$ Treatment effect (control vs. DHA), $P<0.10$.

by: 1) their transformation into other C22:6 and C20:5 isomers as a result of enzymatic isomerization, 2) hydrogenation of their double bonds, and 3) shortening of their carbon chain. The disappearance of DHA and EPA from cultures from cultures after $24 \mathrm{~h}$ of incubation clearly demonstrates the ability of ruminal microorganisms to transform DHA and EPA into other FA. Although both DHA and EPA disappeared from cultures after $24 \mathrm{~h}$ of incubation, the amount that disappeared was not equal. The disappearance of EPA was greater (Figure 1) than that of DHA when incubated at similar levels $(5,10$, and $15 \mathrm{mg}$ per culture). Increasing the levels of DHA and EPA in cultures seems to have some influence on their disappearance. For example, the total amount of that DHA disappeared from cultures decreased from 4.1 to $3.3 \mathrm{mg}$ per culture when the DHA level increased from 15 to $20 \mathrm{mg}$, respectively. The same trend was also seen when EPA level increased from 10 
Table 2. Changes in milligrams of fatty acids per culture flask over time with added eicosapentaenoic acid (EPA) (mg/flask).

\begin{tabular}{|c|c|c|c|c|c|c|c|c|}
\hline \multirow{2}{*}{ Fatty acids } & & \multicolumn{4}{|c|}{ Treatment } & \multirow[b]{2}{*}{$\mathrm{SE}$} & \multicolumn{2}{|c|}{ Contrast $^{1}$} \\
\hline & & Control & 5mg EPA & 10mg EPA & 15mg EPA & & Lin & Quad \\
\hline \multicolumn{9}{|l|}{ C16:0 } \\
\hline & $0-\mathrm{h}$ & 15.9 & 15.9 & 15.5 & 15.8 & 0.25 & 0.86 & 0.36 \\
\hline & $12-\mathrm{h}$ & 21.9 & 22.1 & 20.4 & 20.5 & 0.98 & 0.32 & 0.44 \\
\hline & $24-4$ & 27.7 & 27.7 & 26.1 & 25.3 & $0.23^{*}$ & 0.02 & 0.28 \\
\hline C18:0 & $0-\mathrm{h}$ & 11.7 & 11.3 & 11.2 & 11.3 & $0.15^{*}$ & 0.83 & 0.49 \\
\hline & $12-\mathrm{h}$ & 18.7 & 12.6 & 11.1 & 11.4 & $0.48^{*}$ & 0.19 & 0.20 \\
\hline & $24-4$ & 26.7 & 19.5 & 11.8 & 11.8 & $0.06^{*}$ & $<0.01$ & $<0.01$ \\
\hline & $0-\mathrm{h}$ & 8.6 & 9.6 & 9.0 & 9.1 & 0.14 & 0.05 & 0.33 \\
\hline & $12-\mathrm{h}$ & 6.4 & 8.0 & 8.8 & 9.4 & $0.40 *$ & 0.10 & 0.88 \\
\hline & $24-4$ & 4.6 & 5.7 & 9.3 & 9.5 & $0.34^{*}$ & 0.01 & 0.08 \\
\hline C18:1 trans & $0-\mathrm{h}$ & 2.0 & 1.8 & 2.1 & 1.7 & 0.22 & 0.65 & 0.32 \\
\hline & $12-\mathrm{h}$ & 7.4 & 11.3 & 10.2 & 9.7 & $0.27 *$ & 0.04 & 0.40 \\
\hline & $24-4$ & 8.8 & 13.7 & 14.4 & 13.4 & $0.43^{*}$ & 0.02 & 0.28 \\
\hline C18:2 & $0-\mathrm{h}$ & 14.9 & 14.8 & 14.1 & 14.5 & 0.42 & 0.82 & 0.39 \\
\hline & $12-\mathrm{h}$ & 7.0 & 7.7 & 8.4 & 10.0 & $0.6^{*}$ & 0.09 & 0.48 \\
\hline & $24-4$ & 2.9 & 3.0 & 4.9 & 6.2 & $0.32 *$ & 0.02 & 0.64 \\
\hline \multicolumn{4}{|l|}{ C18:3 } & & 0.9 & & 0.93 & 0.94 \\
\hline & $12-\mathrm{h}$ & 0.4 & 0.4 & 0.4 & 0.4 & 0.02 & 0.68 & 0.65 \\
\hline & $24-4$ & 0.2 & 0.2 & 0.2 & 0.2 & 0.01 & 0.55 & 0.72 \\
\hline \multicolumn{9}{|l|}{ C22:0 } \\
\hline & $12-\mathrm{h}$ & 0.2 & 0.2 & 0.2 & 0.2 & 0.00 & 0.58 & $\begin{array}{l}.01 \\
0.78\end{array}$ \\
\hline & $24-4$ & 0.2 & 0.2 & 0.2 & 0.2 & 0.01 & 0.30 & 0.51 \\
\hline \multicolumn{9}{|l|}{ C24:0 } \\
\hline & $0-\mathrm{h}$ & 0.2 & 0.2 & 0.2 & 0.2 & 0.01 & 0.91 & 0.89 \\
\hline & $12-\mathrm{h}$ & 0.2 & 0.2 & 0.2 & 0.2 & 0.01 & 0.68 & 0.65 \\
\hline & $24-4$ & 0.2 & 0.2 & 0.2 & 0.2 & 0.02 & 0.32 & 0.36 \\
\hline C20:5 (EPA) & $0-\mathrm{h}$ & 0.0 & 4.6 & 9.7 & 14.8 & $0.19 *$ & $<0.01$ & 0.76 \\
\hline & $12-\mathrm{h}$ & 0.0 & 0.4 & 4.3 & 10.2 & $0.29 *$ & $<0.01$ & 0.08 \\
\hline \multirow{2}{*}{\multicolumn{9}{|c|}{ Others $^{2}$}} \\
\hline & & & & & & & & \\
\hline & $0-\mathrm{h}$ & 0.0 & 0.0 & 0.1 & 0.1 & $0.02 *$ & 0.03 & 0.57 \\
\hline & $12-\mathrm{h}$ & 0.5 & 2.1 & 3.3 & 3.1 & $0.13^{*}$ & 0.03 & 0.03 \\
\hline \multicolumn{9}{|l|}{ Total FA (flask) } \\
\hline & $0-\mathrm{h}$ & 55.3 & 59.6 & 63.5 & 69.1 & $1.47 *$ & 0.04 & 0.69 \\
\hline \multicolumn{8}{|l|}{ EPA disap ${ }^{3}$} & $>0.01$ \\
\hline EPA disap & $12-\mathrm{h}$ & 0.0 & 4.2 & 5.4 & 4.5 & 0.18 & 0.26 & 0.02 \\
\hline & $24-4$ & 0.0 & 4.7 & 8.2 & 7.2 & 0.05 & $<0.01$ & $<0.01$ \\
\hline
\end{tabular}

${ }^{1}$ Contrast $=$ probability of a linear (Lin) or quadratic (Quad) effect of the level of added EPA.

${ }^{2}$ Unidentified long-chain fatty acids.

${ }^{3} \mathrm{EPA}$ disappearance (mg/flask).

$*$ Treatment effect (control vs. EPA), $P<0.10$.

to $15 \mathrm{mg}$. Gulati et al. (1999) also observed the same effect when they incubated fish oil (source of DHA and EPA) at different levels in cultures of ruminal microorganisms. They observed a higher degree of $\mathrm{BH}$ for DHA and EPA when fish oil was incubated at less than 1 $\mathrm{mg} / \mathrm{mL}$ of ruminal fluid, but as the level of fish oil increased in cultures, the degree of $\mathrm{BH}$ for DHA and EPA decreased. The contrasting results regarding DHA and EPA BH between Ashes et al. (1992), who reported negligible hydrogenation for DHA and EPA, and that of Doreau and Chilliard (1997), who reported $>80 \% \mathrm{BH}$ for DHA and EPA, may be explained by the level of fish oil used in these experiments. For example, Ashes et al (1992) incubated fish oil at $5 \mathrm{mg} / \mathrm{mL}$ of ruminal fluid, which would be equivalent to incubating $50 \mathrm{mg}$ of DHA and EPA in our studies.

When comparing the disappearance of DHA and EPA with free C18:2 n-6 in mixed ruminal cultures (Figure 


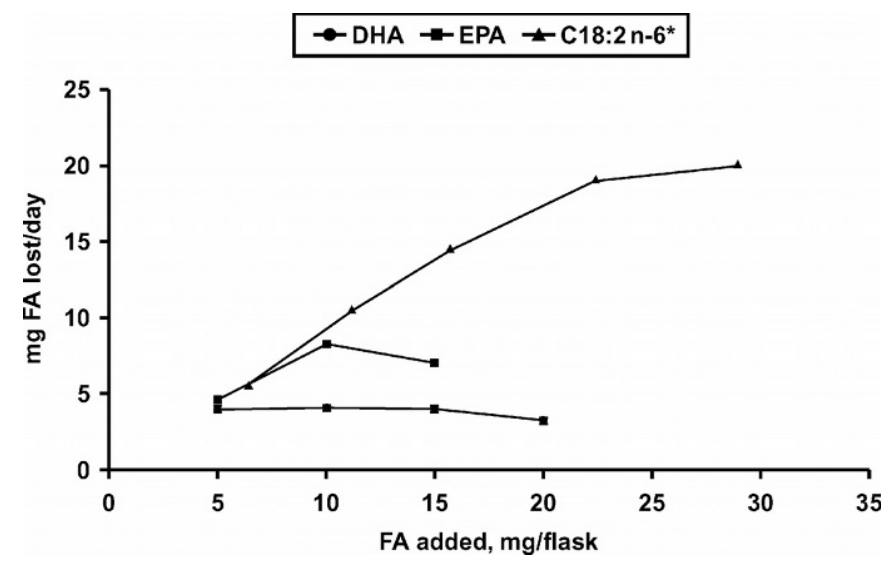

Figure 1. Disappearance of docosahexaenoic acid, eicosapentaenoic acid, and C18:2 n-6 from cultures after $24 \mathrm{~h}$ of incubation. * Adapted from Jenkins (unpublished, 2001).

1), C18:2 n-6 disappearance increased as the level in cultures increased, reaching a maximum at $25 \mathrm{mg}$, then leveling off demonstrating a greater capability of ruminal microorganisms to hydrogenate C18:2 n-6. These differences in disappearance of DHA, EPA, and C18:2 $\mathrm{n}-6$ from cultures when incubated at similar levels may suggest either the presence of different isomerase enzymes with different activities for each FA or the same isomerase enzyme but with different affinity to FA.

The additions of DHA and EPA to cultures have also influenced the disappearance of C18:2 n-6 (Tables 1 and 2). Although C18:2 n-6 was higher $(P<0.10)$ at $0 \mathrm{~h}$ for control compared with other DHA levels, C18:2 n6 concentration after $24 \mathrm{~h}$ of incubation was lower $(P$ $<0.10)$ for the control indicating a reduction in C18:2 $\mathrm{n}-6 \mathrm{BH}$ with added DHA. The $\mathrm{BH}$ of $\mathrm{C} 18: 2 \mathrm{n}-6$ linearly $(P<0.10)$ decreased as the level of DHA in cultures increased (Table 1). Compared with control, BH of C18:2 n- 6 was reduced by $20 \%$ when $20 \mathrm{mg}$ of DHA was added to cultures (Table 1). The same effect was seen when EPA was added (Table 2). The addition of 10 and $15 \mathrm{mg}$ of EPA to cultures reduced the disappearance of $\mathrm{C} 18: 2 \mathrm{n}-6$ by 20 and $30 \%$, respectively, compared with control. This reduction in C18:2 n-6 BH may explain the increase in milk C18:2 n-6 concentrations observed by Cant et al. (1997), Offer et al. (1999), and Kitessa et al. (2001b) when fish oil was added to animals diet.

The disappearance of oleic acid (C18:1 n-9) from cultures showed a different pattern than that of C18:2 n6. (Tables 1 and 2). The addition of $5 \mathrm{mg}$ DHA to cultures reduced the disappearance of $\mathrm{C} 18: 1 \mathrm{n}-9$ from $46 \%$ (control) to $10 \%$. Furthermore, the incubation of DHA at 10,15 , and $20 \mathrm{mg}$ levels unexpectedly increased the concentration of C18:1 n-9 in cultures after $24 \mathrm{~h}$ of incubation (Table 1). A similar decline in the disappearance of C18:1 n-9 was also seen with the addition of 10 and $15 \mathrm{mg}$ EPA to cultures (Table 2). This decline in C18:1 n-9 disappearance with added DHA and EPA may have resulted from inhibiting the reductase enzyme activity in ruminal microorganisms, which is responsible for the terminal hydrogenation of C18:1 n9 to C18:0. The possibility of DHA and EPA or their derivatives inhibiting reductase activity is supported by the fact that C18:0 levels did not increase after 24 $\mathrm{h}$ of incubation when DHA and EPA were added to cultures compared with control (Tables 1 and 2). An alternative explanation for the decline in C18:1 n-9 disappearance is that DHA and EPA may have promoted the conversion of trans FA (such as trans-9 C18:1) into C18:1 n-9. Proell et al. (2002) reported a small conversion of C18:1 trans-9 into C18:1 n-9 when they used ${ }^{13} \mathrm{C}$-labeled trans-9 $\mathrm{C} 18: 1$ in vitro. Even though the possibility of C18:1 n-9 being synthesized directly from DHA and EPA is unlikely due to the absence of the double bond at carbon 9 in DHA and EPA, it is still a possibility that a migration of $\mathrm{cis}$-double bond could have occurred resulting in C18:1 n-9 formation. Others have also reported a reduction in C18:0 concentration in ruminal digesta (AbuGhazaleh et al., 2002), duodenal FA flow (Scollan et al., 2001) and in milk fat content (Offer et al., 1999; Donovan et al., 2000) when fish oil was added to animals diet.

Additions of DHA and EPA to ruminal cultures have also affected trans-C18:1 FA concentrations (Tables 1 and 2). The concentration of trans-C18:1 FA after $24 \mathrm{~h}$ of incubation was increased by $105,91,82$, and $74 \%$ when DHA was added at $5,10,15$, and $20 \mathrm{mg}$, respectively, compared with control (Table 1). Vaccenic acid (trans-11 C18:1) was the major trans-C18:1 isomer representing 88, 93, 92, and 95\% of total trans-C18:1 FA after $24 \mathrm{~h}$ of incubation when DHA was added at 5,10 , 15 , and $20 \mathrm{mg}$, respectively (data not shown). A similar increase in trans-C18:1 FA concentrations were also seen with added EPA (Table 2). The addition of EPA at 5, 10, and $15 \mathrm{mg}$ increased trans-C18:1 FA after $24 \mathrm{~h}$ by 56, 64, and 55\%, respectively, compared with control. It appears that DHA has a greater ability to promote trans-C18:1 FA accumulation compared with EPA. Previous studies have also observed an increase in ruminal (Kitessa et al., 2001a; AbuGhazaleh et al., 2002) and duodenal (Scollan et al., 2001) trans-C18:1 FA concentration when fish oil was added to animals diet. This increase in trans-C18:1 FA with added DHA and EPA may be caused by inhibiting the reductase activity of ruminal microorganisms, causing the accumulation of trans-C18:1 FA in cultures. However, the possibility that DHA and EPA had directly contributed to trans-C18:1 FA formation can not be ruled out since 

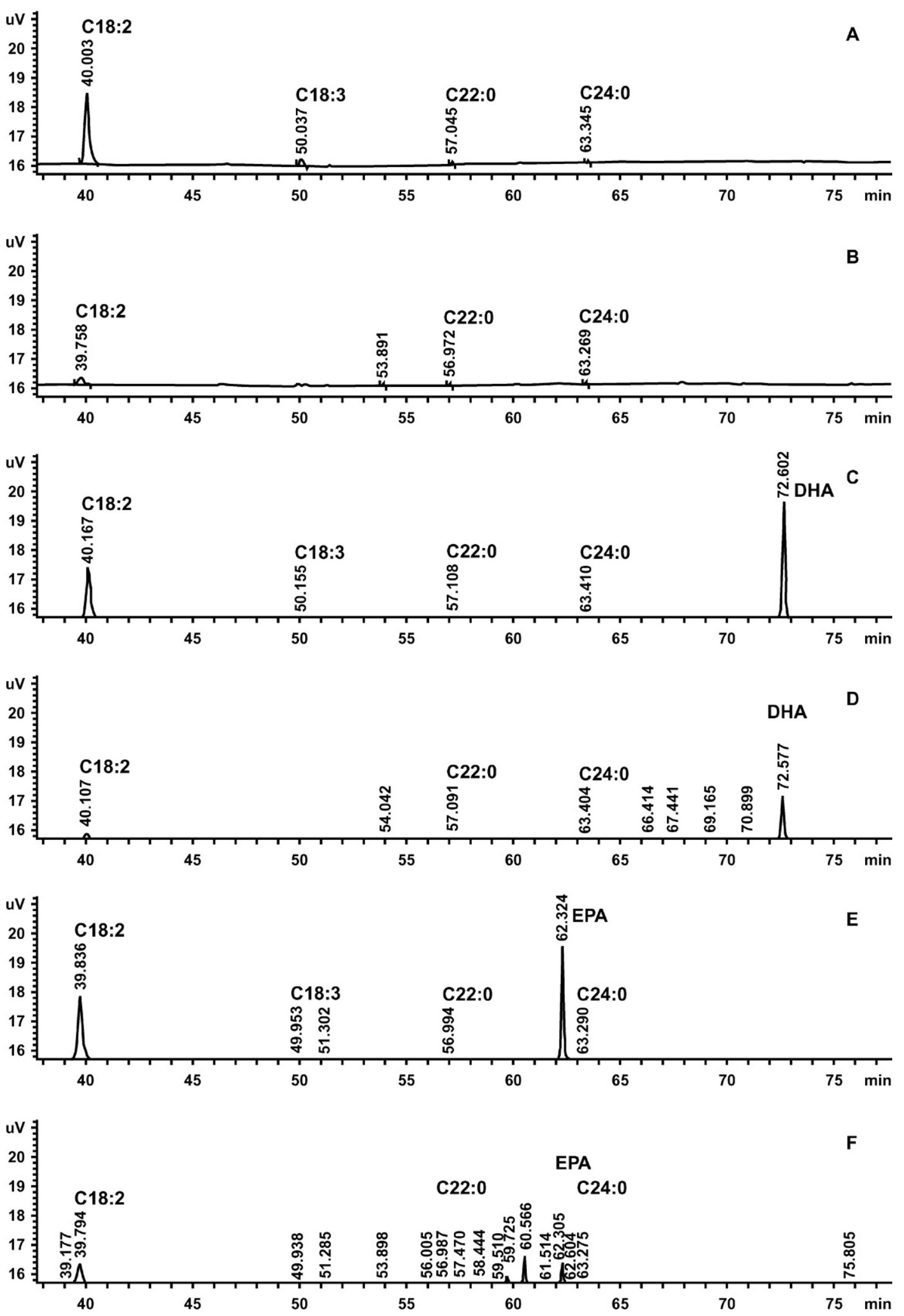

Figure 2. The GLC chromatograms that illustrate the disappearance of docosahexaenoic acid (DHA) and eicosapentaenoic acid (EPA) from cultures and their transformation into other fatty acids. A) control at $0 \mathrm{~h}, \mathrm{~B}$ ) control at $24 \mathrm{~h}, \mathrm{C}) \mathrm{DHA}$ at $0 \mathrm{~h}, \mathrm{D}) \mathrm{DHA}$ at $24, \mathrm{E}) \mathrm{EPA}$ at $0 \mathrm{~h}, \mathrm{~F}) \mathrm{EPA}$ at $24 \mathrm{~h}$. 
the losses in unsaturated FA (C18:1 n-9, C18:2 n-6, C18:3) from cultures after $24 \mathrm{~h}$ of incubation did not account for all the increase in trans-C18:1 FA with the addition of DHA and EPA (Tables 1 and 2). Additionally, the total sum of all unsaturated C18 FA (C18:1, C18:2 n-6, C18:3) increased in DHA and EPA cultures after $24 \mathrm{~h}$ of incubation (Tables 1 and 2).

\section{CONCLUSIONS}

The results from these studies demonstrate the ability of microorganisms from the rumen to transform DHA and EPA to other FA. The maximum transformation per culture of ruminal contents was lower for DHA and EPA than for C18:2 n-6. Percentage of DHA and EPA disappeared declines with increasing initial concentrations of FA.

\section{ACKNOWLEDGMENTS}

Approved as technical contribution number 4889 of the South Carolina Agricultural Experiment Station, Clemson University. Appreciation is extended to Evanne Thies for assistance with FA analysis.

\section{REFERENCES}

AbuGhazaleh A. A., D. J. Schingoethe, A. R. Hippen, K. F. Kalscheur, and L. A. Whitlock. 2002. Fatty acid profiles of milk and rumen digesta from cows fed fish oil, extruded soybeans or their blend. J. Dairy Sci. 85:2266-2276.

Ashes, J. R., B. D. Siebert, S. K. Gulati, A. Z. Cuthbertson, and T. W. Scott. 1992. Incorporation of $n-3$ fatty acids of fish oil into tissue and serum lipids of ruminants. Lipids 27:629-631.

Cant, J. P., A. H. Fredeen, T. Maclntyre, J. Gunn, and N. Crowe. 1997. Effect of fish oil and monensin on milk composition in dairy cows. Can. J. Anim. Sci. 77:125-131.

Chilliard, Y., A. Ferlay, R. M. Mansbridge, and M. Doreay. 2000. Ruminant milk fat plasticity: nutritional control of saturated, polyunsaturated, trans and conjugated fatty acids. Ann. Zootech. 49:181-205.

Donovan, C. D., D. J. Schingoethe, R. J. Baer, J. Ryali, A. R. Hippen, and S. T. Franklin. 2000. Influence of dietary fish oil on conjugated linoleic acid and other fatty acids in milk fat from lactating dairy cows. J. Dairy Sci. 83:2620-2628.
Doreau, M., and Y. Chilliard. 1997. Effects of ruminal or postruminal fish oil supplementation on intake and digestion in dairy cows. Reprod. Nutr. Dev. 37:113-124.

Franklin, S. T., K. R. Martin, R. S. Baer, and D. J. Schingoethe. 1999 Dietary marine algae (Schizochytrium sp.) increases concentrations of conjugated linoleic acid, docosahexanoic acid, and transvaccenic acid of milk in dairy cow. J. Nutr. 129:2048-2052.

Goering, H. K., and P. J. Van Soest. 1970. Forage fiber analysis (apparatus, reagents, procedures, and some applications). Agric. Handbook No. 379. ARS-USDA, Washington, DC.

Gulati, S. K., J. R. Ashes, and T. W. Scott. 1999. Hydrogenation of eicosapentaenoic and docosahexaenoic acids and their incorporation into milk fat. Anim. Feed Sci. Tech. 79:57-64.

Kitessa, S. M., S. K. Gulati, J. R. Ashes, E. Fleck, T. W. Scott, and P. D. Nichols. 2001a. Utilization of fish oil in ruminants I. Fish oil metabolism in sheep. Anim. Feed Sci. Tech. 89:189-199.

Kitessa, S. M., S. K. Gulati, J. R. Ashes, E. Fleck, T. W. Scott, and P. D. Nichols. 2001b. Utilization of fish oil in ruminants II. Transfer of fish oil fatty acids into goats' milk. Anim. Feed Sci. Tech. 89:201-208.

Kramer, J. K. G., V. Fellner, M. E. R. Dugan, F. D. Sauer, M. M. Mosoba, and M. P. Yurawecz. 1997. Evaluating acid and base catalysts in the methylation of milk and rumen fatty acids with special emphasis on conjugated dienes and total trans fatty acids. Lipids 32:1219-1228.

Leaf, A., and J. Y. Korng. 1998. Omega-3 fatty acids and cardiovascular disease. World Rev. Nutr. Dietetics 83:24-37.

Leaf, A. and P. C. Weber. 1988. Cardiovascular effects on n-3 fatty acids. N. Engl. J. Med. 318:549-555.

Maes, M., A. Christophe, J. Delanghe, C. Altamura, C. Neels, and H. Y. Meltzer. 1999. Lowered n-3 polyunsaturated fatty acids in serum phospholipids and cholesteryl esters of depressed patients. Psychiatry Res. 85:275-291.

Mansbridge, R. J., and J. S. Blake. 1997. Nutritional factors affecting the fatty acid composition of bovine milk. Brit. J. Nutr. 78:537-549.

Offer, N. W., M. Marsden, J. Dixon, B. K. Speake, and F. E. Thacker. 1999. Effect of dietary fat supplements on levels of n-3 polyunsaturated fatty acids, trans acids and conjugated linoleic acid in bovine milk. Anim. Sci. 69:613-625.

Proell, J. M., E. E. Mosley, G. L. Powell, and T. C. Jenkins. 2002. Isomerization of stable isotopically labeled elaidic acid to cis and trans monoenes by ruminal microbes. 2002. J. Lipid Res. 43:2072-2076.

Scollan N. D., M. S. Dhanoa, N. J. Choi, W. J. Maeng, M. Enser, and J. D. Wood. 2001. Biohydrogenation and digestion of long chain fatty acids in steers fed on different sources of lipids. J. Agric. Sci. 136:345-355.

Sheard, N. F. 1998. Fish consumption and risk of sudden cardiac death. Nutr. Rev. 56:177-179.

Simopoulos, A. P. 1998. Redefining dietary reference values and food safely. World Rev. Nutr. Dietetics 83:219-222. 